Article

\title{
Multi-Decadal Mangrove Forest Change Detection and Prediction in Honduras, Central America, with Landsat Imagery and a Markov Chain Model
}

\section{Chi-Farn Chen ${ }^{1}$, Nguyen-Thanh Son ${ }^{1, *}$, Ni-Bin Chang ${ }^{2}$, Cheng-Ru Chen ${ }^{3}$, Li-Yu Chang ${ }^{1}$, Miguel Valdez ${ }^{3}$, Gustavo Centeno ${ }^{4}$, Carlos Alberto Thompson ${ }^{5}$ and Jorge Luis Aceituno ${ }^{6}$}

1 Center for Space and Remote Sensing Research, National Central University,

Taoyuan County 32001, Taiwan; E-Mails: cfchen@csrsr.ncu.edu.tw (C.-F.C.);

lychang@csrsr.ncu.edu.tw (L.-Y.C.)

2 Department of Civil, Environmental, and Construction Engineering, University of Central Florida, Orlando, FL 32816, USA; E-Mail: nchang@ucf.edu

3 Department of Civil Engineering, National Central University, Taoyuan County 32001, Taiwan; E-Mails: ccruncu@gmail.com (C.-R.C.); mikevalvas27@hotmail.com (M.V.)

4 Servicio de Información Agroalimentaria, Tegucigalpa 4710, Honduras;

E-Mail: centeno_ga@hotmail.com

5 National Secretary of Natural Resources and Environment, Tegucigalpa 4710, Honduras;

E-Mail: cthompson@serna.gob.hn

6 Institute of Forest Conservation and Development, Tegucigalpa 4710, Honduras;

E-Mail: jluis_9028@yahoo.es

* Author to whom correspondence should be addressed; E-Mail: ntsonait@hotmail.com; Tel.: +886-09330-12400.

Received: 30 September 2013; in revised form: 22 November 2013 / Accepted: 25 November 2013 / Published: 27 November 2013

\begin{abstract}
Mangrove forests play an important role in providing ecological and socioeconomic services for human society. Coastal development, which converts mangrove forests to other land uses, has often ignored the services that mangrove may provide, leading to irreversible environmental degradation. Monitoring the spatiotemporal distribution of mangrove forests is thus critical for natural resources management of mangrove ecosystems. This study investigates spatiotemporal changes in Honduran mangrove forests using Landsat imagery during the periods 1985-1996, 1996-2002, and 2002-2013. The future trend of mangrove forest changes was projected by a Markov chain model to support decision-making for coastal management. The remote sensing data were
\end{abstract}


processed through three main steps: (1) data pre-processing to correct geometric errors between the Landsat imageries and to perform reflectance normalization; (2) image classification with the unsupervised Otsu's method and change detection; and (3) mangrove change projection using a Markov chain model. Validation of the unsupervised Otsu's method was made by comparing the classification results with the ground reference data in 2002, which yielded satisfactory agreement with an overall accuracy of $91.1 \%$ and Kappa coefficient of 0.82 . When examining mangrove changes from 1985 to 2013 , approximately $11.9 \%$ of the mangrove forests were transformed to other land uses, especially shrimp farming, while little effort $(3.9 \%)$ was applied for mangrove rehabilitation during this 28 -year period. Changes in the extent of mangrove forests were further projected until 2020, indicating that the area of mangrove forests could be continuously reduced by 1,200 ha from 2013 (approximately 36,700 ha) to 2020 (approximately 35,500 ha). Institutional interventions should be taken for sustainable management of mangrove ecosystems in this coastal region.

Keywords: Landsat; mangrove forests; image classification; change detection; change projection

\section{Introduction}

Mangroves are a group of tree and shrub species naturally distributed along the intertidal coastlines at tropical and subtropical latitudes. They play a crucial role in stabilizing sediments, preventing soil erosion, and protecting human communities farther inland from natural disasters [1-4]. Mangrove forests are able to filter out pollutants in the sea and sequester carbon dioxide $\left(\mathrm{CO}_{2}\right)$ emitted to the atmosphere due to anthropogenetic activities [5-7]. They also provide a wide range of wildlife habitats for large populations of fish, crabs, birds, and other organisms seeking food, shelter, and breeding and nursing areas. Globally, approximately 3.6 million ha of mangrove forest has been lost during the 1980s-2000s, declining from 18.8 million ha in 1980 to 15.2 million ha in 2005 , mainly due to aquaculture development [8-10]. Approximately $1 \%-2 \%$ of mangrove forests is predicted to be lost per year during the next 100 years. If the current rate of loss continues, the ecological and socioeconomic services provided by mangrove forests will eventually be lost $[5,8,11]$. In general, approximately $20 \%-50 \%$ of mangrove destruction in Latin America since the 1980 s was due to shrimp aquaculture [12]. The phenomenon of mangrove forests degradation in Honduras is worthwhile to receive specific attention, given that Honduras is a developing country in Central America with precious mangrove forests in a fast growing coastal region. Aquacultural development of mangrove waters began in this country in the early 1980s [13,14], with a series of unintended environmental consequences such as direct and indirect changes of the hydrological regime, water pollution, and sedimentation of coastal ecosystems [10,12,15-17]. Thus, understanding the spatiotemporal changes of mangrove forests could provide economists, ecologists, and natural resources managers in Honduras with valuable information to improve management strategies for mangrove ecosystems. 
Remote sensing has been widely applied for forest monitoring and such multi-temporal change detection has proved an indispensable tool for landscape planning for its ability to construct spatiotemporal land-cover data essential for analyzing the interactions between changes in land use and population growth under different scenarios. The high-resolution satellite data acquired from, for example, Worldview-2, Quickbird, Ikonos, and FORMOSAT-2 sensors, could improve the spatial resolution for discriminating land-cover features; however, the data acquired from these satellite sensors have limitations, such as high cost of data acquisition and historical data constraints associated with the changes of mangrove forests over the past decades. The launch of Landsat 8 satellite on 11 February 2013 and the availability of historical Landsat 5 and 7 archives allowed us to investigate the spatiotemporal changes of mangrove forests in Honduras from the early 1980s to 2013.

A number of techniques have been developed for land-cover classification. One of the most commonly used classification methods is the parametric maximum likelihood algorithm because this method has a well-developed theoretical base [18]. Other nonparametric algorithms, including support vector machines [19] and artificial neural networks [20], can perform more complex classification tasks [21,22]; however, these supervised classification algorithms required training samples obtained directly from the original images to perform the classification. Selection of training samples for different land-cover classes was a challenging task due to temporal changes of land-cover types over time. In this study, our purpose was to extract only mangrove forests from multi-temporal Landsat imageries over the past few decades for long-term change analysis and change projection. A simple approach was thus developed for extracting mangrove forests in the study area based on the empirical analysis of Landsat imageries and the unsupervised Otsu's method [23].

The inherent trends of land-cover change can be further examined and projected to aid in decision-making. Several prediction methods including those Markov chain models [24,25], ant colony optimization models [26], and cellular automata models [27,28] have been widely applied to analyze changes of land cover and to project future land-cover scenarios [29-37]. Each model has pros and cons, however. For example, the traditional Markov chain model exhibits better capabilities of descriptive power and simple trend projection of the amount of land-cover change [38], although the spatial changes cannot be simulated and predicted $[39,40]$. The ant colony optimization model can perform combinatorial optimization tasks spatially and temporally; however, its theoretical rules are hard to express in a practical form mathematically [39,41]. Similarly, the cellular automata can simulate dynamic land-cover change processes [42]; but this method requires many components as driving forces for simulation $[39,43]$. Thus, selecting a model for prediction of land-cover changes may not be always driven by the overall accuracy. Unlike previous studies for comparing the accuracies of prediction results among different algorithms alone for urban growth predication, the present work used the traditional Markov chain model to project the likely temporal distribution of the mangrove landscape in the pre-specified coastal region driven by some well-known local socioeconomic factors. The quantitative information achieved from such a projection might be useful for forest managers to devise better plans for long-term management of mangrove ecosystems in the region.

The objectives of this study aim to: (1) develop a mapping approach to investigate changes in the extent of mangrove forests in Honduras using multi-temporal Landsat imageries during the periods 1985-1996, 1996-2002, and 2002-2013; and (2) perform the change projections of mangrove forests for the near future using a Markov chain model. 


\section{Study Area}

We selected a study area sharing a part of the Choluteca and Valle departments situated in the Gulf of Fonseca in the southern part of Honduras (Figure 1), in order to investigate the application potential of multi-temporal change detection of mangrove forests using Landsat imageries and prediction of mangrove forests using a Markov chain model. The study area bordered by Honduras, El Salvador, and Nicaragua is one of the most populated and poor regions in Central America [44]. The region is characterized by a dense population of mangrove forests spatially distributed in coastal fringes, inland lagoons, and riparian habitats connected with the Pacific Ocean. The region has a diverse landscape of mangroves, marshes, mudflats, and lagoons and is thus significant for biodiversity conservation. The mangroves here were found at a range of heights from less than $1 \mathrm{~m}$ in some inland areas and in saline flali to $20 \mathrm{~m}$ along rivers. Due to pressing socioeconomic development and population growth, some parts of the mangrove forests were cleared for other land uses. Since the early 1980s, a number of aquaculture fields, especially small-scale shrimp farms, have been constructed via removing the mangrove forests. The destruction of mangrove forests for shrimp farming has continuously degraded ecological and socioeconomic services of mangrove forests, with associated environmental impacts $[45,46]$.

Figure 1. Map of the study area with a reference to the national geography of Honduras in Central America. The green line (a part of Honduras boundary) was used to generate the study area within a buffer of $5 \mathrm{~km}$. The inset shows the 2013 false-color Landsat image $(\mathrm{RGB}=543)$. The bright red generally relates to mangrove forests.

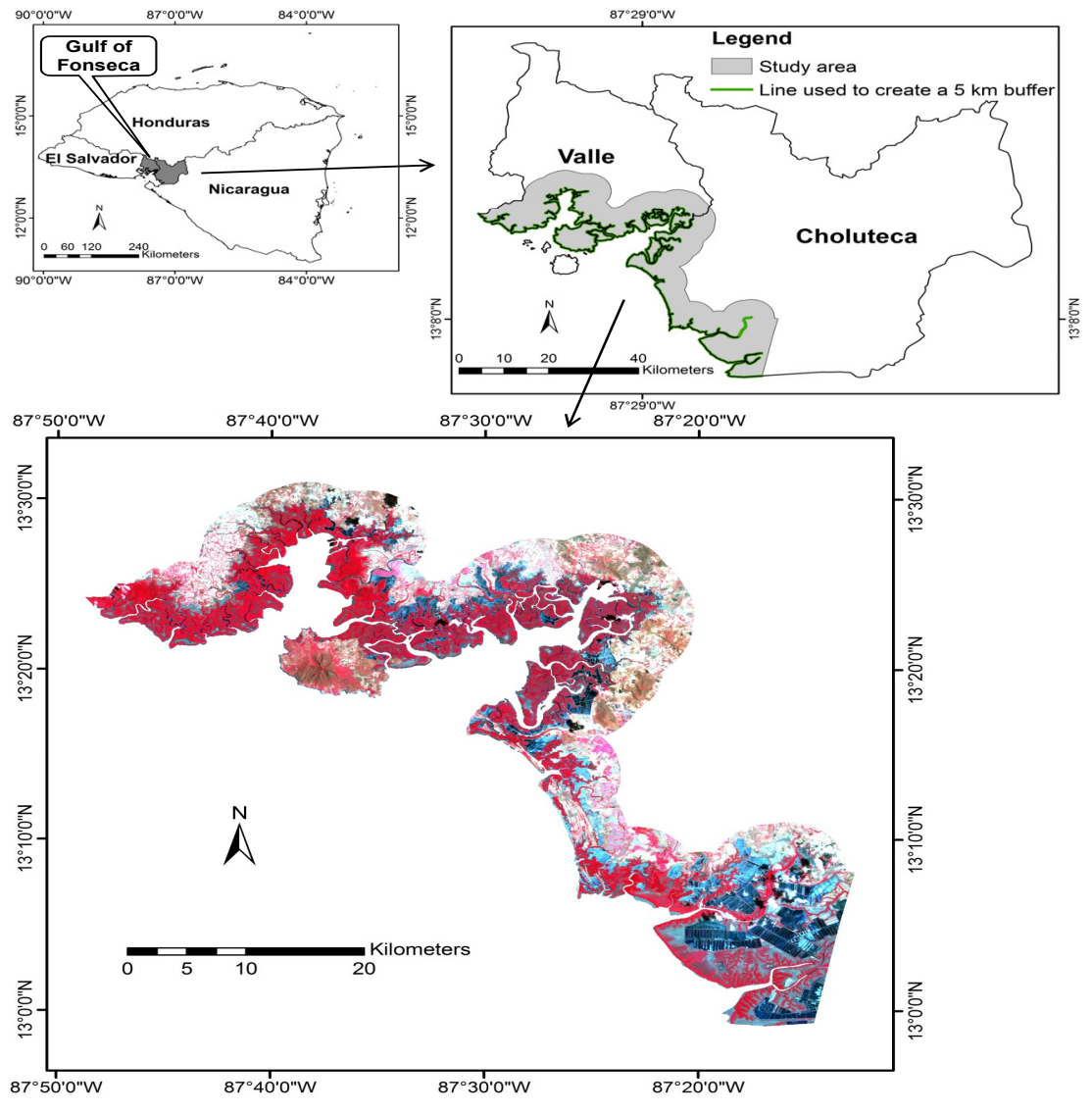




\section{Data Collection}

A suite of Landsat data, including two Landsat Thematic Mapper (TM) images (13 April 1985 and 26 March 1996), a Landsat Enhanced TM Plus (ETM+) image (6 May 2002), and a Landsat 8 (Operational Land Imager, OLI) image (26 April 2013) acquired from the US Geological Survey (USGS), was used in this study. The Landsat TM data have seven spectral bands, with a spatial resolution of $30 \mathrm{~m}$ for bands $1-5$ and 7 . The TM band 6 (thermal infrared) is acquired at $120 \mathrm{~m}$ resolution but is resampled to $30 \mathrm{~m}$ pixels. The Landsat ETM+ data consist of eight spectral bands with a spatial resolution of $30 \mathrm{~m}$ for bands $1-7$. The ETM+ band 6 (thermal infrared) is acquired at $60 \mathrm{~m}$ resolution but is resampled to $30 \mathrm{~m}$ pixels. The Landsat 8 data have nine spectral bands with a spatial resolution of $30 \mathrm{~m}$ for bands $1-7$ and 9. The ETM+ and OLI band 8 (panchromatic band) have a spatial resolution of $15 \mathrm{~m}$. The spectral bands are generally between the optical and short-wavelength-infrared regions, except for band 9 of Landsat 8 data, which has a cirrus wavelength between 1.36 and $1.38 \mu \mathrm{m}$.

Figure 2. Map showing the mangrove forests in the study area extracted from the 2002 land-use map. The dark red and blue pixels randomly extracted from this map were used for computing the Jeffries-Matusita distance $(J M)$ and accuracy assessment of the 2002 classification results.

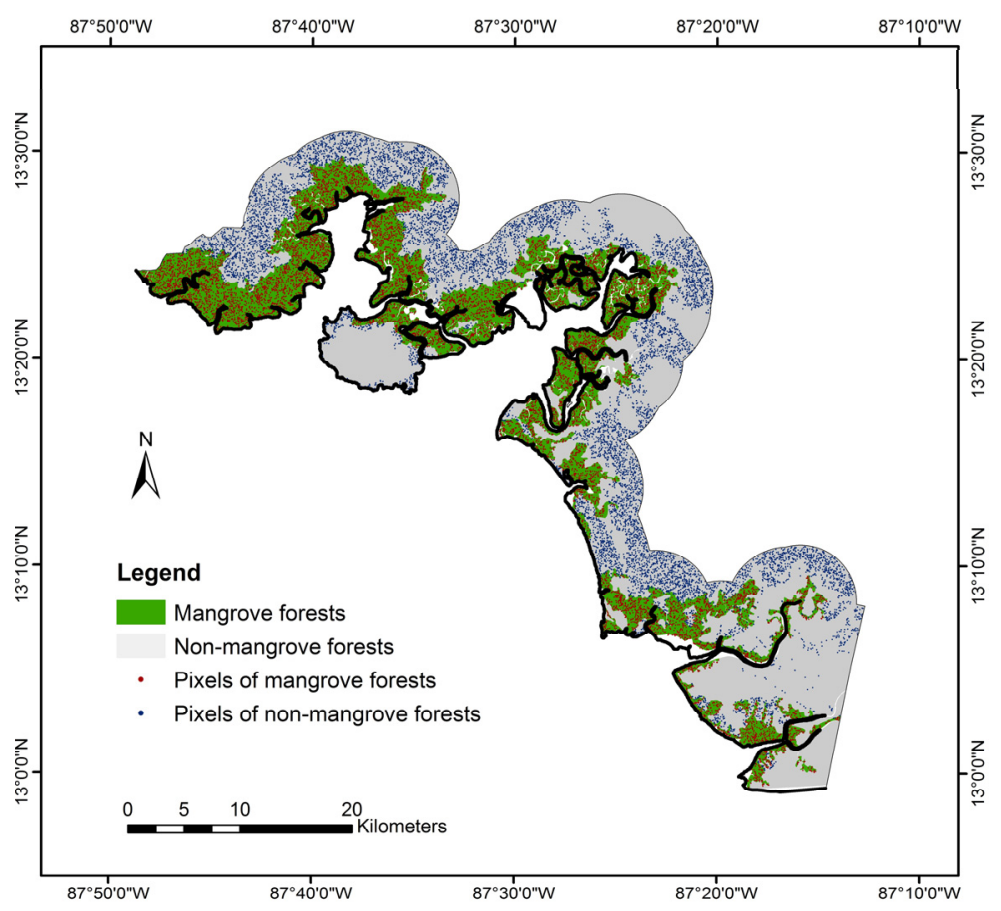

The advanced space-borne thermal emission and reflection radiometer (ASTER) digital elevation model (DEM) (30 m resolution) operated by the National Aeronautics and Space Administration was used for masking out high-elevation areas to ease the change detection analysis. The 2002 land-cover map (scale: 1/250,000) obtained from the Honduras National Institute of Forest Conservation and Development (HNIFCD) was used as a reference data source for crosschecking and accuracy assessment of the classification results. This map produced by HNIFCD was constructed from Landsat 
imageries and validated through field survey data. The HNIFCD map, including nine land-cover classes, was regrouped into two classes, namely mangrove forests and non-mangrove forests. The resultant map was then converted to the raster form with a $30 \mathrm{~m}$ resolution and was used as the ground reference data for accuracy validation of the classification results in this study (Figure 2).

\section{Methodology}

The methodology of this study is composed of three main steps (Figure 3), including: (1) data pre-processing including geometric correction of Landsat images, digital number (DN)-to-reflectance conversion, and reflectance normalization; (2) image classification and change detection; and (3) mangrove change projection using a Markov chain model.

Figure 3. Flowchart of the methodology used for investigating mangrove forests in the study area.

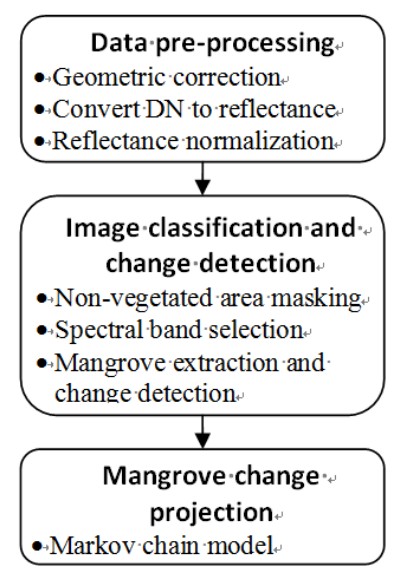

\subsection{Data Pre-Processing}

The Landsat TM and ETM+ images acquired for 1985, 1996, and 2002 were corrected for geometric errors using the 2013 Landsat 8 (OLI) imageries as a reference image. The process was carried out for each image using 20 ground control points, uniformly chosen from distinct features throughout the target image. The results yielded a root mean squared error (RMSE) of less than $15 \mathrm{~m}$. The images were registered to the Universal Transverse Mercator system (zone 16N) and then subset over the study area. The Landsat imageries collected from the USGS have been radiometrically corrected to the level-1 standard. The data are stored as DNs with a range between 0 and 255 to facilitate DN conversion to the top of the atmosphere (TOA) reflectance for comparisons between the satellite images acquired on different days. For the Landsat TM and ETM+ data, Equations (1) and (2) were used to obtain the spectral radiance $\left(L_{\lambda}\right)$ and then TOA reflectance $\left(\rho_{\lambda}\right)$, respectively:

$$
\begin{gathered}
L_{\lambda}=\left(\left(L \max _{\lambda}-L \min _{\lambda}\right) /(Q C A L \max -Q C A L \min )\right) \times(Q C A L-Q C A L \min )+L \min _{\lambda} \\
\rho_{\lambda}=\frac{\pi \times L_{\lambda} \times d^{2}}{E S U N_{\lambda} \times \cos \theta_{s}}
\end{gathered}
$$

where $Q C A L$ is $\mathrm{DN}, L \min _{\lambda}$ is the spectral radiance scales to $Q C A L \min , L \max _{\lambda}$ is the spectral radiance scales to $Q C A L \max , Q C A L \min$ is the minimum quantized calibrated pixel value, $Q C A L \max$ is the 
maximum quantized calibrated pixel value, $d$ is the earth-sun distance, $E S U N_{\lambda}$ is the mean solar exoatmospheric irradiances, and $\theta_{s}$ is the solar zenith angle.

For the Landsat 8 imageries, the TOA reflectance $\left(\rho^{*}\right)$ can be calculated as:

$$
\rho_{\lambda}^{*}=\frac{\rho \lambda^{\prime}}{\sin \theta_{S E}}
$$

where $\rho \lambda^{\prime}$ is the TOA planetary reflectance, with correction for solar angle, and $\theta_{S E}$ is the local sun elevation angle.

The reflectance normalization for 1985, 1996, and 2002 Landsat imageries was also carried out using the 2013 Landsat 8 image as a reference base. This process used the image histogram matching method to make the distribution of brightness values in the 1985, 1996, and 2002 images as close as possible to the 2013 reference image, and to minimize the spectral variations within each land-cover type. Details about histogram matching method can be found in the text of Remote Sensing Digital Image Analysis [47].

\subsection{Image Classification and Change Detection}

\subsubsection{Non-Vegetated Area Masking}

Mangrove forests in the study area are naturally distributed in intertidal coastal wetlands between the land and sea. Based on the initial results obtained from the analysis of the ASTER DEM and the 2002 land-use map (i.e., Figure 2), mangrove forests were generally distributed in areas where the elevation was lower than $30 \mathrm{~m}$. Thus, the areas higher than $30 \mathrm{~m}$ were excluded from the analysis. Non-vegetated areas (e.g., water bodies and built-up areas) were also masked out using the normalized difference vegetation index, where its value was less than 0.25 . This threshold was the most reliable cut-off for separating vegetated and non-vegetated areas in the Landsat images, which was determined based on the results achieved by comparing the masking results with the 2002 land-use map using different thresholds.

\subsubsection{Spectral Band Selection}

The reflectance of leaves in the short wavelength infrared (SWIR) spectrum was attributed to the water absorption and scattering caused by refractive index discontinuities between the leaf cell walls and the intercellular air spaces [48,49]. The low reflectance of mangrove leaves can therefore be attributed to weaker scattering due to a smaller amount of intercellular air space in mangrove leaves compared to non-mangrove leaves. A mixture of mangrove tree crowns and mud or water at the forest floor could explain the low reflectance of mangrove leaves; thus, the low reflectance of mud or water in the SWIR bands would further reduce the reflected radiance of mangrove forests as a whole. This assumption was verified using the $J M$, which measures the spectral separability between land-cover classes [47] using the following form:

$$
J M=2\left(1-e^{-B}\right)
$$

where $B$ is the Bhattacharyya distance [50], expressed as: 


$$
B=\frac{1}{8}\left(m_{1}-m_{2}\right)^{2} \frac{2}{\sigma_{1}^{2}+\sigma_{1}^{2}}+\frac{1}{2} \ln \frac{\sigma_{1}^{2}+\sigma_{1}^{2}}{2 \sigma_{1}^{2} \sigma_{1}^{2}}
$$

where $m_{1}, m_{2}$ and $\sigma_{1}, \sigma_{2}$ are the class means and class variances, respectively. The $J M$ distance has values from 0 to 2 . A value of 2 indicates a complete separability between two classes (i.e., mangrove forests and non-mangrove forests), and lower values indicate a higher possibility of misclassified classes. The $J M$ distance results (Table 1) between the mangrove forests and non-mangrove forests processed for each spectral Landsat band indicated that the higher levels of separability were observed for band $5(J M=1.26)$. This value was relatively smaller than 2 because of the non-mangrove forest class, which was a combination of different vegetation cover types (e.g., agricultural land, grassland/shrubs, and evergreen forests). In general, the $J M$ results suggested that the utilization of band 5 was sufficient to differentiate mangrove forests from non-mangrove forests.

Table 1. The $J M$ distance between mangrove and non-mangrove forests calculated for each Landsat band.

\begin{tabular}{cccc}
\hline $\begin{array}{c}\text { Band } \\
\text { (Landsat TM, ETM+) }\end{array}$ & $\begin{array}{c}\text { Band } \\
\text { (Landsat OLI) }\end{array}$ & Band Name & $\begin{array}{c}\text { Mangrove Forests vs. } \\
\text { non-Mangrove Forests }\end{array}$ \\
\hline 1 & 2 & Blue & 0.85 \\
2 & 3 & Green & 0.98 \\
3 & 4 & Red & 1.11 \\
4 & 5 & NIR & 0.33 \\
5 & 6 & SWIR1 & 1.26 \\
7 & 7 & SWIR2 & 1.20 \\
\hline
\end{tabular}

\subsubsection{Mangrove Extraction and Change Detection}

The Otsu's method [23] was used for classification of mangrove and non-mangrove forests in the study area. This nonparametric and unsupervised method determines an optimal threshold for separating the classification of mangrove forests from the non-mangrove forests. The algorithm converts an intensity image to a binary image while minimizing the intra-class variance of the black and white pixels. The Otsu's optimal threshold $T$ is defined as:

$$
T=\frac{(\bar{\mu} \times w(T)-\mu(T))^{2}}{w(T) \times \mu(T)}
$$

where $w(T)=\sum_{i=0}^{T} p_{i}, \mu(T)=\sum_{i=T+1}^{255} p_{i}, \bar{\mu}=\sum i \times p_{i}, p_{i}$ is the probability of pixels with grey level $i$ in the image. Thus, the pixels that have reflectance values greater than $T$ were classified as non-mangrove forests, otherwise accepted as mangrove forests.

The classification maps containing "salt-and-pepper" noise were removed using the majority filter [51]. Because of the unavailability of land-use maps covering the study area for 1985, 1996, and 2013, this study depended on the 2002 land-use map in Figure 2 to perform the accuracy assessment of the classification results. A total of 10,000 pixels were randomly extracted from this ground reference map (Figure 2) for each class (i.e., mangrove forests $v s$. non-mangrove forests) to compare with those from the 2002 classification maps produced by the Otsu's method. The error matrix using the 
overall, producer, and user accuracies, and Kappa coefficient were calculated to measure the classification accuracy.

From these classification maps, changes in the extent of mangrove forests during the periods 1985-1996, 1996-2002, 2002-2013, and 1996-2013 were examined to gain geographic understanding of the spatiotemporal evolution of mangrove forests in the region.

\subsection{Mangrove Change Projection}

The Markov chain model [24] was used to perform the change projection of mangrove forests within the study area. The period 1996-2013 was chosen for this task because the land-cover changes during this period were relatively stable compared to the previous period, 1985-1996. The Markovian process can be defined as:

$$
v_{t 2}=M v_{t 1}
$$

where $v_{t 1}$ is the input land-cover proportion vector, $v_{t 2}$ is the output land-cover proportion vector, and $M$ is the transition matrix between $t_{1}$ and $t_{2}$ constructed using the probability $\left(p_{i j}\right)$ as follows:

$$
p_{i j}=\frac{n_{i j}}{n_{i}}
$$

where $n_{i}=\sum_{j=1}^{k} n_{i j}, n_{i j}$ is the number of pixels of class $i$ from the first image that were changed to class $j$ in the second image, and $k$ is the total number of classes.

To test the suitability of the Markovian model for land-cover change prediction, we applied the following two statistical tests:

- Pearson's Chi-square $\chi^{2}$ to test the hypothesis of data independence using:

$$
\chi^{2}=\sum_{i} \sum_{k}\left(A_{i k}-E_{i k}\right)^{2} / E_{i k}
$$

where $A_{i k}$ is the actual value of transition matrix (1996-2013), and $E_{i k}$ is the expected value of transition matrix (1996-2002) computed using Chapman-Kolmogorov:

$$
E_{i k}=\sum_{j}\left(E_{i j} \times E_{i k}\right) / E_{j}
$$

where $E_{i j}$ is the transition matrix during 1996-2013, $E_{i k}$ is the transition matrix during 1996-2002 $(i, j$ and $k$ are land-cover classes), and $E_{j}$ is the area of class $j$ in 2002. If the computed $\chi^{2}$ smaller than $\chi^{2}$ from the tables at $\alpha=0.05$ with degrees of freedom $(3-1)^{2}$, the land-cover change was compatible with the hypothesized independence; and

- Goodness-of-fit test to test the suitability of the Markovian hypothesis by examining the observed and transition matrices during 1996-2013:

$$
\chi_{c}^{2}=\sum_{i} \sum_{k}\left(O_{i k}-E_{i k}\right)^{2} / E_{i k}
$$

where $O_{i k}$ is the observed transition probability data during 1996-2013, and $E_{i k}$ is the expected value of the transition matrix during 1996-2013. If $\chi_{c}^{2}$ was smaller than the significant value for the critical region of 0.05 , the hypothesis was accepted, indicating that the data followed the hypothesis of Markovian process. 


\section{Results and Discussion}

\subsection{Spatiotemporal Distribution of Mangrove Forests and Accuracy Assessment Results}

Spatiotemporal distributions of mangrove forests are shown for four particular years of 1985, 1996, 2002, and 2013 reflecting the global trends of decadal changes (Figure 4). The mangrove forests generally sheltered the coastlines, fringes of the estuaries, and riverbanks associated with the brackish water margin between land and sea. The mangrove forests were more concentrated in the upper part of the region because this area was strictly managed by the local authorities as natural reserves for biodiversity conservation. The mangrove forests in the lower part of the region were relatively fragmented due to the development of a number of aquaculture fields, especially small-scale shrimp farms.

Figure 4. Distribution of mangrove forests in the study area in: (a) 1985; (b) 1996; (c) 2002; and (d) 2013.
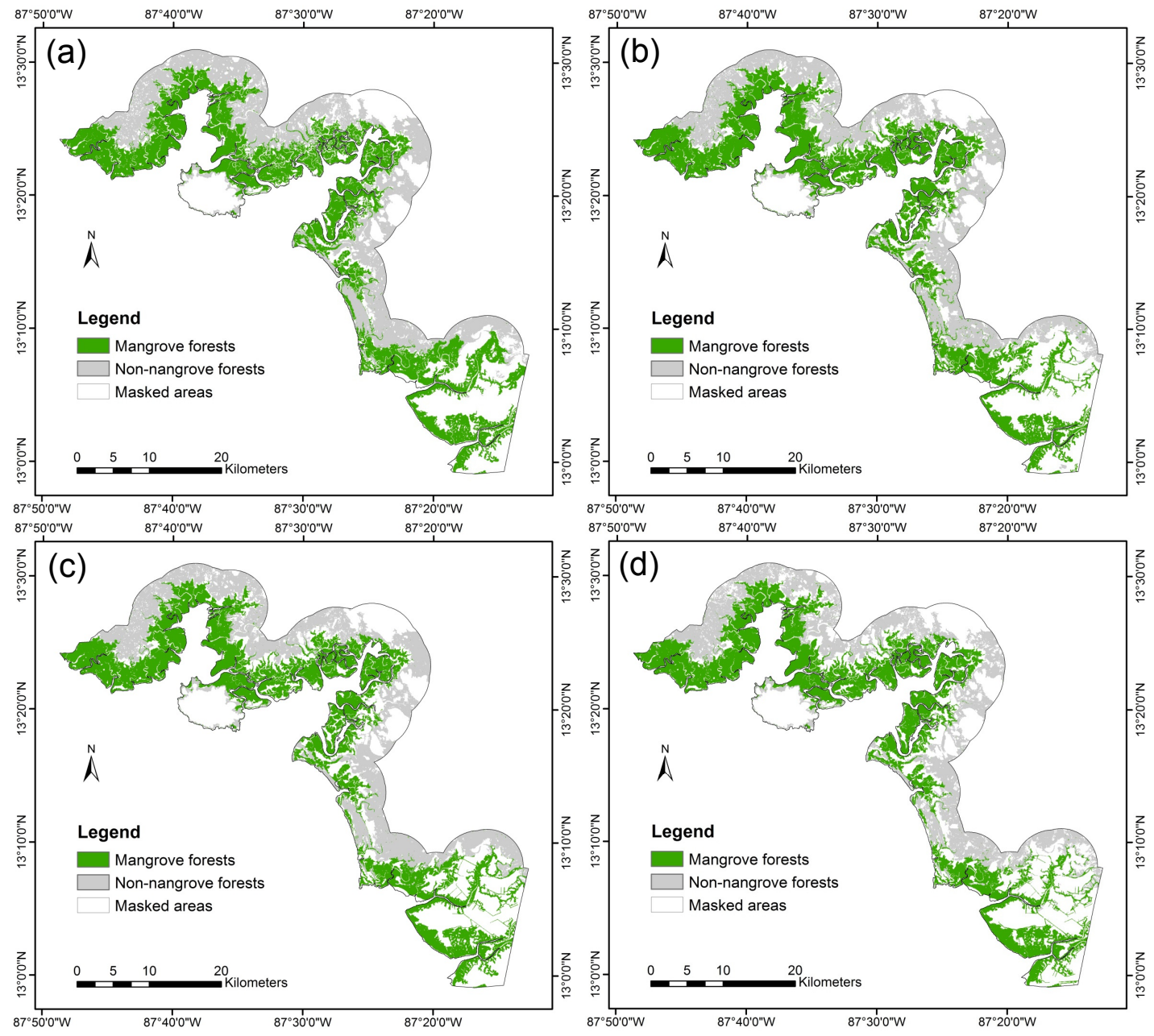

The 2002 classification results were validated using the ground reference data (Figure 2), during which 10,000 pixels for each class (i.e., mangrove forests and non-mangrove forests) were randomly extracted from the ground reference data to compare with those from the 2002 classification map. The comparison indicated satisfactory agreement with the overall accuracy of $91.1 \%$ and a Kappa coefficient 
of 0.82 , respectively (Table 2). Of 10,000 pixels checked to measure the accuracy in each class, the mangrove forest class had a higher producer accuracy level $(94.3 \%)$. The producer accuracy of the non-mangrove forest class was $87.9 \%$, which included a corollary omission error of $12.1 \%$ due to spectral confusion between this class and the mangrove forest class during classification. The spectral confusion was often caused by mixed-pixel problems in areas where road and canal networks developed for transportation could exaggerate the classification errors.

Table 2. Results of accuracy assessment from the classification of the 2002 Landsat $\mathrm{ETM}+$ data.

\begin{tabular}{cccc}
\hline \multirow{2}{*}{ Ground Reference Data (pixels) } & \multicolumn{2}{c}{ Classification Results (pixels) } & \multirow{2}{*}{ Total } \\
\cline { 2 - 3 } & Mangrove Forests & Non-Mangrove Forests & \\
\hline Mangrove forests & 9,425 & 575 & 10,000 \\
Non-mangrove forests & 1,213 & 8,787 & 10,000 \\
Total & 10,638 & 9,362 & 20,000 \\
\hline Producer accuracy (\%) & 94.3 & 87.9 & \\
User accuracy (\%) & 88.6 & 93.9 & \\
Overall accuracy (\%) & 91.1 & & \\
Kappa coefficient & 0.82 & & \\
\hline
\end{tabular}

\subsection{Mangrove Change Detection}

Multi-temporal change analysis in the extent of mangrove forests between different periods (1985-1996, 1996-2002, 2002-2013, and 1985-2013) was also examined (Figure 5). The impacts of land-use change in the region had clearly caused the loss of mangrove forests during 1985-2013 (Table 3). The overall change within the study area during this 28-year period indicated the loss of approximately $11.9 \%$ of mangrove forests, while a small proportion of mangrove forests in the region (3.9\%) was newly planted or rehabilitated. These changes were mainly attributed to the development of aquaculture. Shrimp culture was especially identified as a major cause of direct and indirect loss of mangrove ecosystems due to deforestation for pond construction and changes in hydrology, sedimentation, and water pollution.

Changes in the extent of mangrove forests calculated for each period within the study area indicated that the largest conversion of mangrove forests to non-mangrove forests was observed during the periods of 1985-1996. The loss of mangrove forests during this period was approximately $7.3 \%$, while only $1.4 \%$ was recovered or newly planted at the same time. During the early $1980 \mathrm{~s}$, the shrimp culture was heavily adopted in the region [13,52] owing to the availability of brackish water suitable for shrimp aquaculture development and the high prices of shrimp on the international market [53] that created considerable financial benefits to the local communities. Moreover, although the region was legally characterized as state lands officially managed by governmental institutions during this period, the estuary coastal lowlands were de facto areas. Various management regimes (ranging from private to common property and open access) coexisted [54], which allowed an individual or a corporation to intensify shrimp aquaculture. 
Figure 5. Changes in mangrove forests between: (a) 1985-1996; (b) 1996-2002;

(c) 2002-2013; and (d) 1985-2013.
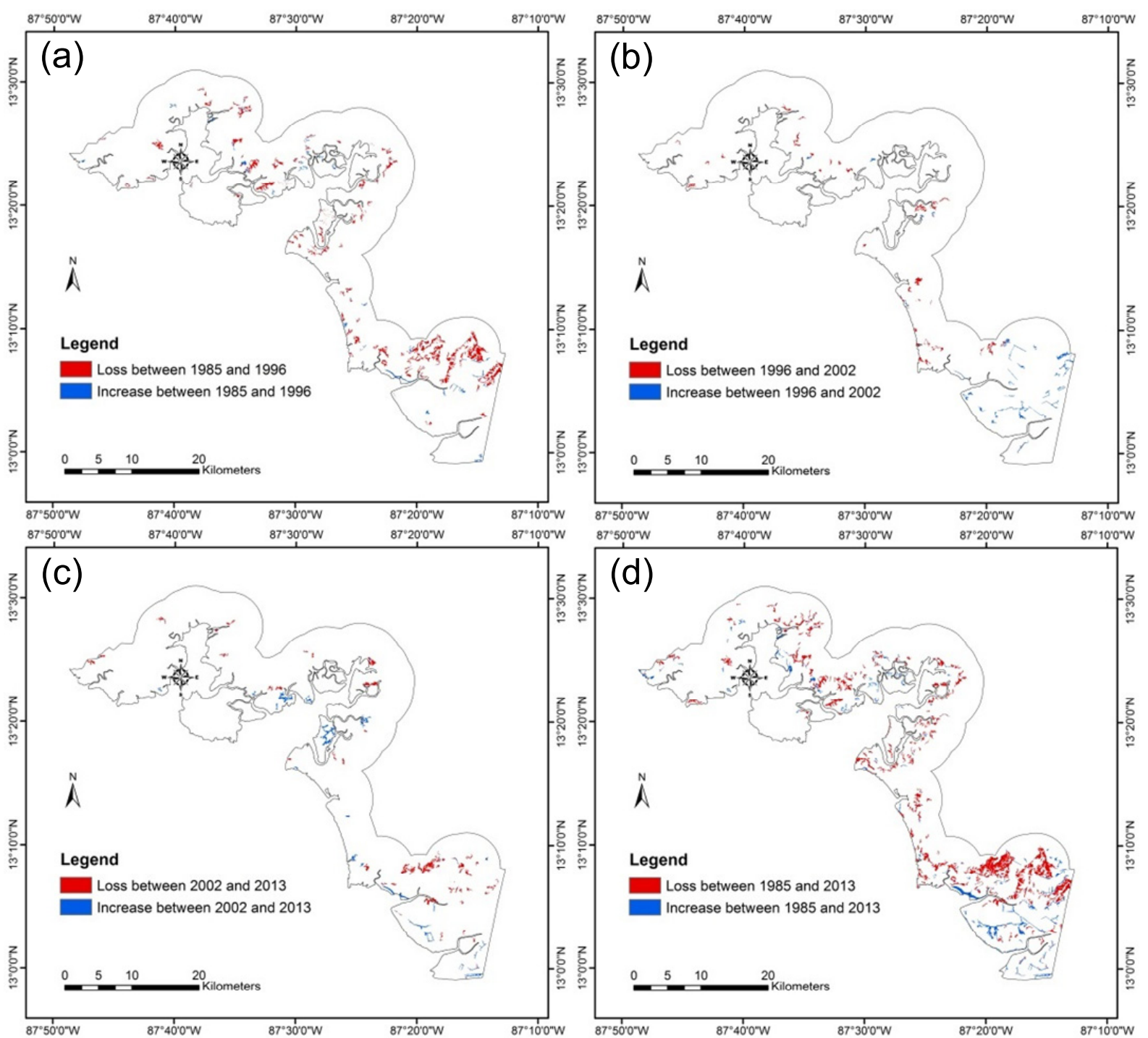

Table 3. Changes in the area of mangrove forests between 1985-1996, 1996-2002, and 2002-2013. The loss and increase of mangrove forests in percentage are calculated as: $\left(s_{j}-s_{i}\right) / s_{i} \times 100$, where $s_{j}$ and $s_{i}$ are the areas of the mangrove forests and non-mangrove forests classes in the $i$ th and $j$ th years, respectively.

\begin{tabular}{ccccc}
\hline \multirow{2}{*}{ Period } & \multicolumn{2}{c}{ Loss } & \multicolumn{2}{c}{ Increase } \\
\cline { 2 - 5 } & ha & $\mathbf{\%}$ & ha & $\mathbf{\%}$ \\
\hline $1985-1996$ & $2,892.3$ & 7.3 & 555.3 & 1.4 \\
$1996-2002$ & 638.6 & 1.7 & 608.7 & 1.6 \\
$2002-2013$ & $1,053.1$ & 2.8 & 771.6 & 2.1 \\
$1985-2013$ & $4,694.1$ & 11.9 & $1,553.2$ & 3.9 \\
\hline
\end{tabular}


THE conversion of mangrove forests to non-mangrove forests was sharply reduced afterward during the period 1996-2002, when only approximately $1.7 \%$ of the mangrove forests were lost for other uses, in part due to mangrove forest recovery efforts in the region $(1.6 \%)$. The decline in deforestation can be partly attributed to better management strategies for mangrove protection to counter potentially negative developments due to shrimp farming. What is even more important is the emergence of reduced shrimp production due to the occurrence of shrimp diseases (Taura and white spot shrimp diseases) coupled with the effects of Hurricane Mitch in 1999 [12,55]. The magnitude of Hurricane Mitch was overwhelming, flooding the study area with approximately $7 \mathrm{~m}$ of water (a.s.1.) for a week, causing substantial changes in biophysical conditions of the region immediately following the event, and impacting sediment load patterns for two years.

From 2002 to 2013, the conversion of mangrove forests to other uses $(2.8 \%)$ and mangrove rehabilitation (2.1\%) both slightly increased. The increased area of mangrove forests was partly due to the recovery of mangrove forests after Hurricane Mitch [56]; the slight increase in loss of mangrove forests could be attributed to pressing economic development and changes in international prices of shrimp markets, thereby reflecting in the rate of shrimp-farm construction in the region. Moreover, the number of small-scale shrimp culture farmers with less technical expertise declined due to the spread of shrimp diseases and water pollution, which led to lower shrimp output and reduced ability to compete with industrial counterparts.

\subsection{Mangrove Change Projection}

The hypothesis of data independence over different periods evaluated using $\chi^{2}$ test indicated a value of $2.795 \times 10^{6}$, which was larger than 9.488 in the critical region of 0.05 with $(3-1)^{2}$ degrees of freedom. Thus, the hypothesis of statistical independence for these data was rejected, indicating that land-cover change was dependent on previous land development creating the basis for modeling the Markov chain. The goodness-of-fit test $\left(\chi_{c}^{2}\right)$ used to examine the suitability of the Markovian model for the land-cover change also revealed a value of 9.343, supporting the hypothesis that the land-cover change follows the Markovian process. The model using the transition matrix (during 1996-2013) was thus constructed to predict the land-cover change for 2020.

The land-cover change was projected using Markov's transition probability matrices (Table 4) generated for the period 1996-2013. The generalization ability of these transition matrices was tested by predicting the land cover in 2002. The predicted results compared with the 2002 classification results indicated less variation between the two datasets (Figure 6), confirming that the transition matrices between 1996 and 2013 could be effective for predicting land-cover in the near future. In this study, the land-cover change was predicted for 2020. The results indicated that the area of mangrove forests would decline from approximately 36,700 ha in 2013 to 35,500 ha in 2020 , and that the conversion of mangrove forests to non-mangrove forests for other land uses such as shrimp farming would continue. 
Table 4. Transitional probabilities during 1996-2013.

\begin{tabular}{cccc}
\hline 1996-2002 & Mangrove Forests & Non-Mangrove Forests & Masked Areas \\
\hline Mangrove forests & 0.532 & 0.179 & 0.288 \\
Non-mangrove forests & 0.124 & 0.375 & 0.501 \\
Masked areas & 0.236 & 0.201 & 0.563 \\
\hline 1996-2013 & & & \\
\hline Mangrove forests & 0.305 & 0.234 & 0.460 \\
Non-mangrove forests & 0.290 & 0.237 & 0.473 \\
Masked areas & 0.297 & 0.236 & 0.468 \\
\hline
\end{tabular}

Figure 6. Comparison between land-cover projected results achieved from the transition matrix during 1985-2013 and the classification results for 2002 and 2013.

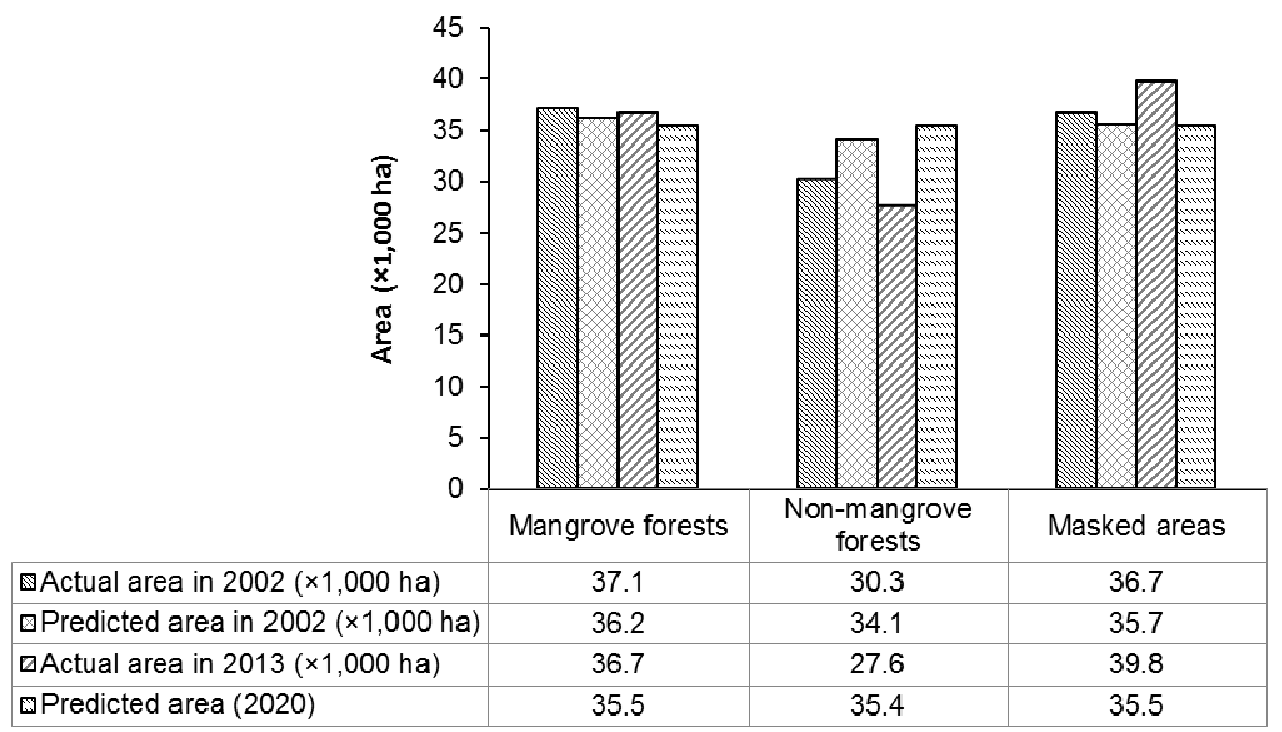

Changes in the extent of mangrove forests in the form of deforestation for constructing aquaculture farms, residential settlements, and salt production fields into the terrestrial mangroves were mainly driven by two factors: economic development and population growth [57-59]. The population in the study region directly or indirectly relying on the mangrove resources was more than a million people. The population density (persons per $\mathrm{km}^{2}$ ) has more than doubled from approximately 32 in 1980 to 68 in 2010 and is predicted to reach 82 in 2020 [60,61]. Studies in the Gulf of Fonseca also indicated that trends in mangrove deforestation persisted due to the increasing demands of aquaculture development and fuel-wood consumption in response to a growing population [62]. The loss of mangrove forests reduced environmental suitability, resulting in an increased incidence of disease outbreaks that could ultimately lead to the failure of aquacultural production. Further research on rehabilitating unproductive farms into sustainable operations might contribute to reduced degradation of neighboring mangrove areas.

The mangrove projection for 2020 in this study was made based only on the transition probability matrices. Although spatiotemporal changes in mangrove forests were driven by various determinants including socioeconomic factors and related policies, our anticipated results could serve as a useful baseline for understanding impacts of aquaculture developments in the future. Thus, institutional 
measures could be taken to adjust the trends of land-cover change and to improve the management of mangrove ecosystems in the region.

\section{Conclusions}

Our findings from multi-temporal change detection and prediction support the application potential of the proposed method for mapping mangrove forests within the study area, during the periods 1985-1996, 1996-2002, and 2002-2013. The classification results indicated close agreement with the ground reference data. The overall and Kappa coefficients were 91.1\% and 0.82, respectively. From 1985 to 2013 , approximately $11.9 \%$ of the mangrove forests were lost for other uses, especially shrimp farming, while a little effort (3.9\%) was made to restore/rehabilitate the mangrove forests during this 28-year period. The greatest loss (approximately 7.3\%) was observed during 1985-1996 due to the substantial development of shrimp culture adopted in the 1980s. The decrease in conversion of mangrove forests to other uses noted afterward was probably due to the occurrence of shrimp diseases coupled with the impacts Hurricane Mitch. The trends of land-cover change were also examined using the Markov chain model; the results revealed the suitability of this method for land-cover change projection with the aid of multi-temporal change detection. The area of mangrove forests predicted for 2020 showed a possible reduction of 1,200 ha from 2013 (approximately 36,700 ha) to 2020 (approximately 35,500 ha); thus, institutional or policy interventions may be taken into account to improve management of mangrove forests in the region. The overall efforts in this study demonstrate the effectiveness of the proposed method used for investigating and predicting the spatiotemporal changes of mangrove forests in Honduras based on multiple Landsat satellites. The results achieved from this study could provide planners with invaluable quantitative information for sustainable management of mangrove ecosystems in the region.

\section{Acknowledgments}

This study is financed by the Taiwan International Cooperation and Development Fund (ICDF-101-011). The financial support is gratefully acknowledged. We thanked the Honduras National Institute of Forest Conservation and Development for providing the ground reference data.

\section{Conflicts of Interest}

The authors declare no conflict of interest.

\section{References}

1. Brown, C.; Corcoran, E.; Herkenrath, P.; Thonell, J. Marine and Coastal Ecosystems and Human Well-Being: Synthesis; United Nations Environment Programme, Division of Early Warning Assessment: Nairobi, Kenya, 2006.

2. Giri, C.; Ochieng, E.; Tieszen, L.L.; Zhu, Z.; Singh, A.; Loveland, T.; Masek, J.; Duke, N. Status and distribution of mangrove forests of the world using earth observation satellite data. Glob. Ecol. Biogeogr. 2011, 20, 154-159. 
3. Costanza, R. Visions, values, valuation, and the need for an ecological economics. Bioscience 2001, 51, 459-468.

4. Nagelkerken, I.; Blaber, S.J.M.; Bouillon, S.; Green, P.; Haywood, M.; Kirton, L.G.; Meynecke, J.O.; Pawlik, J.; Penrose, H.M.; Sasekumar, A.; et al. The habitat function of mangroves for terrestrial and marine fauna: A review. Aquat. Bot. 2008, 89, 155-185.

5. Duke, N.C.; Meynecke, J.O.; Dittmann, S.; Ellison, A.M.; Anger, K.; Berger, U.; Cannicci, S.; Diele, K.; Ewel, K.C.; Field, C.D.; et al. A world without mangroves? Science 2007, 317, 41-42.

6. Jennerjahn, T.; Ittekkot, V. Relevance of mangroves for the production and deposition of organic matter along tropical continental margins. Naturwissenschaften 2002, 89, 23-30.

7. Dittmar, T.; Hertkorn, N.; Kattner, G.; Lara, R.J. Mangroves, a major source of dissolved organic carbon to the oceans. Glob. Biogeochem. Cy. 2006, 20, doi:10.1029/2005GB002570.

8. Valiela, I.; Bowen, J.L.; York, J.K. Mangrove forests: One of the world's threatened major tropical environments. BioScience 2001, 51, 807-815.

9. Giri, C.; Zhu, Z.; Tieszen, L.L.; Singh, A.; Gillette, S.; Kelmelis, J.A. Mangrove forest distributions and dynamics (1975-2005) of the tsunami-affected region of Asia†. J. Biogeogr. 2008, 35, 519-528.

10. FAO. The World's Mangroves 1980-2005; Food and Agriculture Organization of the United Nations: Rome, Italy, 2007.

11. Alongi, D.M. Present state and future of the world's mangrove forests. Environ. Conserv. 2002, $29,331-349$.

12. Tobey, J.; Clay, J.; Vergne, P. Maintaining a Balance: The Economic, Environmental and Social Impacts of Shrimp Farming in Latin America; Coastal Resources Center, University of Rhode Island: Narragansett, RI, USA, 1998.

13. Stanley, D.L. The economic impact of mariculture on a small regional economy. World Development 2003, 31, 191-210.

14. FAO. Global Production Statistics 1950-2005; Food and Agriculture Organization of the United Nations: Rome, Italy, 2005.

15. Stonich, S.C.; Bort, J.R.; Ovares, L.L. Globalization of shrimp mariculture: The impact on social justice and environmental quality in central America. Soc. Nat. Resourc. 1997, 10, 161-179.

16. Paez-Osuna, F. The environmental impact of shrimp aquaculture: A global perspective. Environ. Pollut. 2001, 112, 229-231.

17. Paez-Osuna, F. The environmental impact of shrimp aquaculture: Causes, effects, and mitigating alternatives. Environ. Manag. 2001, 28, 131-140.

18. Bolstad, P.; Lillesand, T.M. Rapid maximum likelihood classification. Photogram. Eng. Remote Sens. 1991, 57, 67-74.

19. Boser, B.E.; Guyon, I.; Vapnik, V. Annual Workshop on Computational Learning Theory. In A Training Algorithm for Optimal Margin Classiers, 5th ed.; ACM Press: New York, NY, USA, 1992.

20. Benediktsson, J.A.; Swain, P.H.; Ersoy, O.K. Neural Network Approaches vs. Statistical Methods in Classification of Multisource Remote Sensing Data. In Proceedings of IEEE International Geoscience and Remote Sensing Symposium (IGARSS'89) \& 12th International Canadian Symposium on Remote Sensing, Vancouver, BC, Canada, 10-14 July 1989; pp. 489-492. 
21. Karkee, M.; Steward, B.L.; Tang, L.; Aziz, S.A. Quantifying sub-pixel signature of paddy rice field using an artificial neural network. Comput. Electron. Agric. 2009, 65, 65-76.

22. Moody, A.; Gopal, S.; Strahler, A.H. Artificial neural network response to mixed pixels in coarse-resolution satellite data. Remote Sens. Environ. 1996, 58, 329-343.

23. Otsu, N. A threshold selection method from gray-level histograms. IEEE Trans. Syst. Man Cybern. 1979, 9, 62-66.

24. Lambin, E.F. Modelling Deforestation Processes: A Review; Office for Official Publications of the European Community: Brussels, Belgium, 1994.

25. Glenn, D.C.; Lewin, R.K.; Peet, T.T.V. Plant Succession: Theory and Prediction; Chapman \& Hall: London, UK, 1992.

26. Dorigo, M.; Stützle, T. The Ant Colony Optimization Metaheuristic: Algorithms, Applications, and Advances. In Handbook of Metaheuristics; Glover, F., Kochenberger, G., Eds.; Springer: New York, NY, USA, 2003; Volume 57, pp. 250-285.

27. Von Neumann, J.; Burks, A.W. Theory of Self-Reproducing Automata; University of Illinois Press: Champaign, IL, USA, 1966.

28. Araya, Y.H.; Cabral, P. Analysis and modeling of urban land cover change in Setúbal and Sesimbra, Portugal. Remote Sens. 2010, 2, 1549-1563.

29. Coppedge, B.; Engle, D.; Fuhlendorf, S. Markov models of land cover dynamics in a southern Great Plains grassland region. Landsc. Ecol. 2007, 22, 1383-1393.

30. Yang, X.; Zheng, X.-Q.; Lv, L.N. A spatiotemporal model of land use change based on ant colony optimization, Markov chain and cellular automata. Ecol. Model. 2012, 233, 11-19.

31. Petit, C.; Scudder, T.; Lambin, E. Quantifying processes of land-cover change by remote sensing: Resettlement and rapid land-cover changes in south-eastern Zambia. Int. J. Remote Sens. 2001, 22, 3435-3456.

32. Rajitha, K.; Mukherjee, C.K.; Vinu Chandran, R.; Prakash Mohan, M.M. Land-cover change dynamics and coastal aquaculture development: A case study in the East Godavari delta, Andhra Pradesh, India using multi-temporal satellite data. Int. J. Remote Sens. 2010, 31, 4423-4442.

33. López, E.; Bocco, G.; Mendoza, M.; Duhau, E. Predicting land-cover and land-use change in the urban fringe: A case in Morelia city, Mexico. Landsc. Urban Plan. 2001, 55, 271-285.

34. Mitsova, D.; Shuster, W.; Wang, X. A cellular automata model of land cover change to integrate urban growth with open space conservation. Landsc. Urban Plan. 2011, 99, 141-153.

35. Silva, E.A.; Ahern, J.; Wileden, J. Strategies for landscape ecology: An application using cellular automata models. Prog. Plan. 2008, 70, 133-177.

36. Han, J.; Hayashi, Y.; Cao, X.; Imura, H. Application of an integrated system dynamics and cellular automata model for urban growth assessment: A case study of Shanghai, China. Landsc. Urban Plan. 2009, 91, 133-141.

37. Adhikari, S.; Southworth, J. Simulating forest cover changes of Bannerghatta National Park based on a CA-markov model: A remote sensing approach. Remote Sens. 2012, 4, 3215-3243.

38. Lepš, J. Mathematical modelling of ecological succesion-A review. Folia Geobot. Phytotax 1988, 23, 79-94.

39. Du, Y.; Wen, W.; Cao, F.; Ji, M. A case-based reasoning approach for land use change prediction. Expert Syst. Appl. 2010, 37, 5745-5750. 
40. Arsanjani, J.J.; Kainz, W.; Mousivand, A.J. Tracking dynamic land-use change using spatially explicit Markov Chain based on cellular automata: The case of Tehran. Int. J. Image Data Fusion 2011, 2, 329-345.

41. Dorigo, M.; Maniezzo, V.; Colorni, A. Ant system: Optimization by a colony of cooperating agents. IEEE Trans. Syst. Man Cybern. Part B Cybern. 1996, 26, 29-41.

42. Wagner, D.F. Cellular automata and geographic information systems. Environ. Plan. B Plan. Design 1997, 24, 219-234.

43. Shafizadeh Moghadam, H.; Helbich, M. Spatiotemporal urbanization processes in the megacity of Mumbai, India: A Markov chains-cellular automata urban growth model. Appl. Geogr. 2013, 40, 140-149.

44. Stonich, S.C. Struggling with Honduran poverty: The environmental consequences of natural resource-based development and rural transformations. World Dev. 1992, 20, 385-399.

45. Southworth, J.; Munroe, D.; Nagendra, H. Land cover change and landscape fragmentation-Comparing the utility of continuous and discrete analyses for a western Honduras region. Agric. Ecosyst. Environ. 2004, 101, 185-205.

46. Stonich, S.C. The promotion of non-traditional agricultural exports in Honduras: Issues of equity, environment and natural resource management. Dev. Change 1991, 22, 725-755.

47. Richards, J.A.; Jia, X. Remote Sensing Digital Image Analysis: An Introduction, 4th ed.; Springer-Verlag: Berlin, Germany, 2006; p. 439.

48. Woolley, J.T. Reflectance and transmittance of light by leaves. Plant Physiol. 1971, 47, 656-662.

49. Gausman, H.W. Leaf reflectance of near-infrared. Photogram. Eng. 1974, 40, 183-191.

50. Bhattacharyya, A. On a measure of divergence between two statistical populations defined by their probability distributions. Bull. Calcutta Math. Soc. 1943, 35, 99-109.

51. Lim, J.S. Two-Dimensional Signal and Image Processing; Prentice Hall: Upper Saddle River, NJ, USA, 1990.

52. FAO. State of World Aquaculture; Food and Agriculture Organization of the United Nations: Rome, Italy, 2006.

53. FAO. The State of World Fisheries and Aquaculture; FAO Fisheries and Aquaculture Department, Food and Agriculture Organization of the United Nations: Rome, Italy, 2007.

54. Benessaiah, K. Mangroves, Shrimp Aquaculture and Coastal Livelihoods in the Estero Real, Gulf of Fonseca, Nicaragua; McGill University: Montreal, QC, Canada, 2008.

55. FAO. Regional Review on Aquaculture Development in Latin America and the Caribbean; Food and Agriculture Organization of the United Nations: Rome, Italy, 2006.

56. Cahoon, D.R.; Hensel, P. Hurricane Mitch: A Regional Perspective on Mangrove Damage, Recovery and Sustainability; USGS: New York, NY, USA, 2002.

57. Polidoro, B.A.; Carpenter, K.E.; Collins, L.; Duke, N.C.; Ellison, A.M.; Ellison, J.C.; Farnsworth, E.J.; Fernando, E.S.; Kathiresan, K.; Koedam, N.E.; et al. The loss of species: Mangrove extinction risk and geographic areas of global concern. PLoS One 2010, 5, doi:10.1371/journal.pone.0010095.

58. Ellison, A.M. Managing mangroves with benthic biodiversity in mind: Moving beyond roving banditry. J. Sea Res. 2008, 59, 2-15. 
59. Gilman, E.L.; Ellison, J.; Duke, N.C.; Field, C. Threats to mangroves from climate change and adaptation options: A review. Aquat. Bot. 2008, 89, 237-250.

60. UN. World Population Prospects: The 2012 Revision; United Nations: New York, NY, USA, 2012.

61. IDB. Integrated Ecosystem Management of the Gulf of Fonseca; Inter-American Development Bank (IDB): Washington, DC, USA, 2007.

62. Benítez, M.; Machado, M.; Erazo, M.; Aguilar, J.; Campos, A.; Durón, G.; Aburto, C.; Chanchan, R.; Gammage, S. A Platform for Action for the Sustainable Management of Mangroves in the Gulf of Fonseca; International Center for Research on Women: Washington, DC, USA, 2000.

(C) 2013 by the authors; licensee MDPI, Basel, Switzerland. This article is an open access article distributed under the terms and conditions of the Creative Commons Attribution license (http://creativecommons.org/licenses/by/3.0/). 